\title{
A novel small molecule hydroxamate preferentially inhibits HDAC6 activity and tumour growth
}

\author{
M Kaliszczak ${ }^{1}$, S Trousil ${ }^{1}$, O Åberg ${ }^{1}$, M Perumal ${ }^{1}$, Q-D Nguyen ${ }^{1}$ and E O Aboagye ${ }^{\star, 1}$ \\ ${ }^{1}$ Comprehensive Cancer Imaging Centre, Department of Surgery and Cancer Faculty of Medicine, Imperial College London, \\ Hammersmith Hospital, Room 240, MRC Cyclotron Building, Du Cane Road, London W12 ONN, UK
}

Background: This study investigates whether a histone deacetylase subtype 6 (HDAC6) inhibitor could be used in the treatment of solid tumours.

Methods: We evaluated the effect of a novel inhibitor, C1A, on HDAC6 biochemical activity and cell growth. We further examined potential of early noninvasive imaging of cell proliferation by $\left[{ }^{18} \mathrm{~F}\right]$ fluorothymidine positron emission tomography $\left(\left[{ }^{18} \mathrm{~F}\right] \mathrm{FLT}-\mathrm{PET}\right)$ to detect therapy response.

Results: C1A induced sustained acetylation of HDAC6 substrates, $\alpha$-tubulin and HSP90, compared with current clinically approved HDAC inhibitor SAHA. C1A induced apoptosis and inhibited proliferation of a panel of human tumour cell lines from different origins in the low micromolar range. Systemic administration of the drug inhibited the growth of colon tumours in vivo by $78 \%$. The drug showed restricted activity on gene expression with $<0.065 \%$ of genes modulated during $24 \mathrm{~h}$ of treatment. C1A treatment reduced tumour $\left[{ }^{18} \mathrm{~F}\right] \mathrm{FLT}$ uptake by 1.7 -fold at $48 \mathrm{~h}$, suggesting that molecular imaging could provide value in future studies of this compound.

Conclusion: C1A preferentially inhibits HDAC6 and modulates HDAC6 downstream targets leading to growth inhibition of a diverse set of cancer cell lines. This property together with the favourable pharmacokinetics and efficacy in vivo makes it a candidate for further pre-clinical and clinical development.

Histone deacetylase (HDAC) enzymes that affect the acetylation status of histones and various cellular proteins have been recognised as therapeutic targets in central nervous system disorders and cancer ( $\mathrm{Xu}$ et al, 2007; Kazantsev and Thompson, 2008; Haberland et al, 2009; Marks and Xu, 2009). Two inhibitors, vorinostat (SAHA) and romidepsin, have been approved by the FDA for treatment of cutaneous T cell lymphoma (Duvic and Vu, 2007; Piekarz et al, 2009). There are 18 HDACs, which are classified structurally into class I (HDAC1, HDAC2, HDAC3, HDAC8), class IIa (HDAC4, HDAC5, HDAC7, HDAC9), class IIb (HDAC6, HDAC10), class III (sirtuins; SIRT1-7) and class IV (HDAC11) groups. Class I HDACs are mostly nuclear, ubiquitously expressed and display enzymatic activity towards histone substrates. Class II members shuttle between the nucleus and the cytoplasm, target primarily non-histone substrates and their expression is tissue specific. In parallel with the explosion of HDAC research, the number of HDAC inhibitor (HDACI) drug candidates has grown exponentially in the last decade. Most HDACIs reported to date inhibit multiple HDAC isoforms, particularly HDAC1 and HDAC3, and although they have desirable antiproliferative effects, a number of these also elicit profound side effects, including bone marrow suppression, weight loss, fatigue and cardiac arrhythmias (Bruserud et al, 2007; Marsoni et al, 2008). The discovery of HDACIs with different isoform profiles or indeed isoform selective inhibition is important to elucidate the mechanism of action of specific HDAC enzymes,

*Correspondence: Dr EO Aboagye; E-mail: eric.aboagye@imperial.ac.uk

Revised 23 November 2012; accepted 28 November 2012;

published online 15 January 2013

(C) 2013 Cancer Research UK. All rights reserved 0007-0920/13

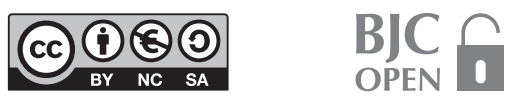


and may hold greater promise than their non-selective counterparts, by minimising toxicity.

HDAC6 has recently emerged as an attractive target for the treatment of cancer (Boyault et al, 2007; Lee et al, 2008; Kawada et al, 2009; Rivieccio et al, 2009). HDAC6 was shown to be the deacetylase for a diverse set of substrates involved in tumourigenesis, such as HSP90, $\alpha$-tubulin, cortactin and peroxiredoxins, but unlike other HDACs, inhibition of HDAC6 is believed not to be associated with severe toxicity; HDAC6 knockout in mice does not lead to embryonic lethality (Hubbert et al, 2002; Haggarty et al, 2003; Bali et al, 2005; Zhang et al, 2007; Parmigiani et al, 2008; Witt et al, 2009; Kaluza et al, 2011). To date, HDAC6 selective inhibitors (tubacin, tubastatin A) have only contributed to validate HDAC6 as a target, but their unfavourable pharmacokinetic (PK) profiles have prevented them from further pre-clinical and clinical development, making them only good research tools (Haggarty et al, 2003; Butler et al, 2010).

Here we report the development of a novel HDAC6 inhibitor, $\mathrm{C} 1 \mathrm{~A}$. We show that, $\mathrm{C} 1 \mathrm{~A}$ induces cell death and significant growth inhibition in a panel of cancer cells, and because of its favourable $\mathrm{PK}$ profile, is efficacious in solid tumours in vivo.

\section{MATERIALS AND METHODS}

HDAC deacetylase activity. HDAC enzyme inhibition was assessed as described elsewhere, using recombinant enzymes and 7-amino-4-methylcoumarin (AMC)-labelled substrates from p53 residues 379-382: the activities of HDACs 1, 2, 3, 6 and 10 were assessed using the substrate RHKKAc; HDAC8 activity was assayed using a specific substrate RHKAcKAc (Schultz et al, 2004; Butler et al, 2010). Activities of the Class IIa HDACs (HDAC4, 5, 7, 9) were assessed using a Class IIa-specific substrate (R, Acetyl-Lys(trifluoroacetyl)-AMC; Lahm et al, 2007).

Growth inhibitory assay. Drug concentrations that inhibited $50 \%$ of cell growth $\left(\mathrm{GI}_{50}\right)$ were determined using a sulphorhodamine $\mathrm{B}$ technique as described elsewhere (Vichai and Kirtikara, 2006). All cell lines were treated for $72 \mathrm{~h}$ on day 2 unless otherwise stated.

Immunoblotting. Cells were cultured for $24 \mathrm{~h}$ and subsequently treated with different compounds: C1A (synthesised in-house), SAHA and 17-AAG (LC Laboratories, Woburn, MA, USA) at the indicated concentrations for 4 or $24 \mathrm{~h}$. Protein samples were subsequently prepared by lysing cells in RIPA buffer (Invitrogen, Paisley, UK) supplemented with protease and phosphatase inhibitor cocktails (Sigma, St Louis, MO, USA). Tumour samples were prepared as follows: excised and snap-frozen tumour xenografts were homogenised in RIPA lysis buffer with the PreCellys 24 homogeniser and CK14 bead-containing tubes (2 cycles of $25 \mathrm{~s}$ at 6500 r.p.m.; Bertin Technologies, Montigny le Bretonneux, France). For immunoprecipitation experiments, cell lysates were incubated with primary antibody for $1 \mathrm{~h}$ at $4{ }^{\circ} \mathrm{C}$ and subsequently incubated with protein A/G Plus-Agarose beads (Santa Cruz Biotechnologies, Santa Cruz, CA, USA) overnight, centrifuged, washed, resuspended in lysis buffer and subject to standard western blot procedures.

Cell cycle analysis. Cells were treated with C1A or SAHA for $24 \mathrm{~h}$. Collected cells were fixed with ethanol and stained with propidium iodide in PBS for $3 \mathrm{~h}$. Cell cycle distributions were determined using flow cytometry (FACS canto, Becton Dickinson, Oxford, UK) and analysed using the flowJo software (Treestar Inc, Ashland, OR, USA). In each analysis, 10000 events were recorded.

Caspase-3/7 assay. Caspase-3/7 activity was determined using Promega's caspase-3/7 assay according to the manufacturer's instructions (Promega, Madison, WI, USA). In brief, cells were incubated for $1 \mathrm{~h}$ with Caspase-Glo reagent, and the enzymatic activity of caspase-3/7 was measured using a TopCount NXT microplate luminescence counter (PerkinElmer, Waltham, MA, USA) and normalised to protein content.

PK profiling. C1A was prepared in 10\% DMSO, 10\% solutol HS15 (BASF) and 10\% Tween 20 in PBS, and administrated at $20 \mathrm{mg} \mathrm{kg}^{-1}$ intraperitoneally (i.p.) to female BALB/c mice (Harlan, Bicester, UK). Full details are described in Supplementary Information. All animal experiments were done by licensed investigators in accordance with the United Kingdom Home Office Guidance on the Operation of the Animal (Scientific Procedures) Act 1986 (HMSO, London, UK, 1990) and within guidelines set out by the United Kingdom National Cancer Research Institute Committee on Welfare of Animals in Cancer Research (Workman et al, 2010).

Tumour xenografts. HCT-116 cells $\left(5 \times 10^{6}\right)$ were injected subcutaneously in $100 \mu \mathrm{l}$ volumes into the flanks of female nu/ nu-BALB/c athymic nude mice (Harlan). Tumour measurements were performed daily and volumes were calculated using the formula (length $(\mathrm{mm})) \times($ width $(\mathrm{mm})) \times($ depth $(\mathrm{mm})) \times \pi / 6$. When tumours reached a volume of $50-100 \mathrm{~mm}^{3}$, treatment with different compounds was initiated. Throughout the 14-day treatment period, animal weights and tumour volumes were determined daily.

$\left[{ }^{18} \mathrm{~F}\right]$ Fluorothymidine positron emission tomography imaging. HCT-116 cells $\left(5 \times 10^{6}\right)$ cells were injected on the back of female $\mathrm{nu} / \mathrm{nu}-\mathrm{BALB} / \mathrm{c}$ mice. At 24 or $48 \mathrm{~h}$ post treatment with $\mathrm{C} 1 \mathrm{~A}$ given at $40 \mathrm{mg} \mathrm{kg}^{-1} \mathrm{QD}$, the animals were scanned on a dedicated small animal PET scanner (Siemens Inveon PET module) following a bolus intravenous injection of $\sim 3.7 \mathrm{MBq}$ of $\left[{ }^{18} \mathrm{~F}\right]$ fluorothymidine $\left(\left[{ }^{18} \mathrm{~F}\right] \mathrm{FLT}\right)$ as previously described (Leyton et al, 2006a,b, 2008; Nguyen et al, 2009). The normalised uptake value at $60 \mathrm{~min}$ post injection $\left(\mathrm{NUV}_{60}\right)$ was used for comparisons (Nguyen et al, 2009).

Ki-67 immunostaining. Tumours treated with C1A or vehicle were excised after imaging, fixed in formalin, embedded in paraffin and cut into $5.0 \mu \mathrm{m}$ sections, and tumour proliferation was determined as previously described (Leyton et al, 2006a). Data from 10 randomly selected fields of view per section were captured using an Olympus BX51 microscope (Olympus, Southend-on-Sea, $\mathrm{UK})$ at $\times 400$ magnification. Ki-67-positive cells were counted using ImageJ software (NIH, Bethesda, MD, USA) and expressed as a percentage of total cells counted.

Active caspase-3 and TUNEL immunohistochemistry assay. Tumour sections were processed for active caspase-3 and DNA degradation with terminal deoxynucleotidyl transferase dUTP nick end labelling (TUNEL) as previously described (Nguyen et al, 2009).

Gene array. Animals were treated with $\mathrm{C} 1 \mathrm{~A}$ at $40 \mathrm{mg} \mathrm{kg}^{-1}$ (or vehicle) and the tumours excised and snap-frozen $24 \mathrm{~h}$ after injection. Total RNA was extracted from tumours using RNeasy mini Kit (Qiagen, Crawley, UK) and hybridised to Affymetrix human genome U219 microarray (Affymetrix, Santa Clara, CA, USA). Studies were performed under contract by AlphaMetrix Biotech (Rödermark, Germany). A differential expression of 1.5 -fold was selected as a cut-off value.

Statistical analyses. Statistical analyses were done using GraphPad prism software. Differences between groups were analysed by two tailed Student's $t$-tests. Differences in tumour growth in nude mice were analysed by repeated measures two-way ANOVA. $P$-values $<0.05$ using a $95 \%$ confidence intervals were considered significant. Data are reported as mean \pm s.e.m. of at least three independent experiments unless otherwise stated. ${ }^{\star} P<0.05$, ${ }^{* *} P<0.005,{ }^{* *} P<0.0001$, NS, not significant.

Additional methods. Additional methodology is described in Supplementary Information-Materials and Methods. 


\section{RESULTS}

C1A is an effective HDAC6 inhibitor. C1A was developed based on the structure of naturally occurring pan HDACIs trichostatin A and SAHA. Although maintaining the hydroxamate part of the molecule, responsible for the binding to the $\mathrm{Zn}^{2+}$ pocket of HDAC in general, the aromatic nitrogen mustard moiety, originally introduced to enhance duration of drug action, was found to enhance preferential binding to HDAC6 (Figure 1A; Finnin et al, 1999). A molecular modelling approach was used to illustrate the preferential affinity of C1A to HDA6 catalytic domain (cd) II (Figure 1B and C) relative to HDAC1cd (Figure 1D and E). In many aspects, the binding mode for the two isoforms, HDAC1 and HDAC6, is very similar. Both are bound to the $\mathrm{Zn}^{2+}$ ion in the bottom of the pocket in a bidentate fashion. There are hydrophobic interactions between the conjugated carbon chain of $\mathrm{C} 1 \mathrm{~A}$ and the side chains of Phe150 and Phe205 in HDAC1cd and the side chains of Phe620 and Phe680 in HDAC6cdII. However, there are important differences as can be seen by comparing the water accessible surfaces. For HDAC1cd, the aniline mustard binds to the surface of the protein at an unfavourable solvent-exposed area. The HDAC6cdII pocket is much wider and can much better accommodate the inhibitor, and the aniline mustard moiety binds to a well-defined hydrophobic groove, which contributes to the observed isoform selectivity.

C1A inhibited class I/II HDACs, and sirtuins, with highest affinity for HDAC6 $\left(\mathrm{IC}_{50}=479 \mathrm{nM}\right)$ versus $\mathrm{HDAC1}\left(\mathrm{IC}_{50}=14 \mu \mathrm{M}\right.$; Figure $1 \mathrm{~F}$ and Supplementary Table S1). HDAC8 was also inhibited by $\mathrm{C} 1 \mathrm{~A}$ at submicromolar concentrations (Supplementary Table S1). Initial reports suggesting that HDAC8 drug inhibition had little effect in solid tumour-derived cell lines (e.g., HCT-116) triggered our attention towards HDAC6 inhibition and its application in our experimental models of cancer (Balasubramanian et al, 2008).

C1A treatment affects known HDAC6 substrates. We evaluated the effect of C1A on HDAC6 substrates. In human colon cancer HCT-116 cells, we observed an increase in the acetylation of $\alpha$-tubulin and HSP90, known substrates of HDAC6, as early as $4 \mathrm{~h}$ after $1 \mu \mathrm{M} \mathrm{C1A}$ treatment (Figure 2A and B). The effect of C1A on acetylation of $\alpha$-tubulin was drug concentration-dependent at 4 and $24 \mathrm{~h}$ (Figure $2 \mathrm{~B}$ and C). Treatment with the clinically licensed broad-spectrum inhibitor, SAHA, also increased acetylation of $\alpha$-tubulin. Unlike C1A, however, SAHA increased acetylation of histone $\mathrm{H} 3$, a biomarker for inhibition of class I HDACs (Figure 2A and C). When treated continuously for $4 \mathrm{~h}(10 \mu \mathrm{M})$ and drug was subsequently removed by washing to mimic intermittent dosing in vivo, acetylation of $\alpha$-tubulin was maintained for $3 \mathrm{~h}$ after washout of C1A but not with SAHA (Figure 2D). These results show that $\mathrm{C1A}$ is associated with a sustained effect on HDAC6 response that would allow the drug to be dosed less frequently.

The loss of chaperone activity of HSP90 is a functional consequence of its acetylation (Scroggins et al, 2007). CDK4 is a recognised client protein of the HSP90 chaperone and is degraded upon HSP90 inhibition (Banerji et al, 2005). Both C1A and SAHA were associated with a decline of CDK4 expression, consistent with HSP90 inhibition (Figure 2E). As a control, treatment of cells with the HSP90 inhibitor, 17-AAG, also decreased CDK4 expression in these cells (Figure 2E). Treatment with positive control tubastatin A, a HDAC6 inhibitor tool compound, was also associated with a decline of CDK4, concomitant with a drug concentration-dependent increase of the acetylated form of $\alpha$-tubulin (Supplementary Figure 1).

Similarly, HCT-116 cells transfected with HDAC6 shRNA showed increased acetylation of $\alpha$-tubulin concomitant with a decrease of CDK4 (Supplementary Figure S2).

C1A does not promote non-specific DNA alkylation. We wondered if the presence of a nitrogen mustard moiety in C1A promoted non-specific DNA alkylation. As DNA alkylating agents will generally be more active in cell lines deficient in the DNA repair machinery, we tested the potency of the drug in cell lines deficient in DNA repair proteins. We showed that, in contrast to the DNA alkylating agent chlorambucil, the growth inhibitory potency of $\mathrm{C} 1 \mathrm{~A}$ was not affected by DNA repair defects (Figure $2 \mathrm{~F}$ ), suggesting that the nitrogen mustard moiety in $\mathrm{C} 1 \mathrm{~A}$ does not induce non-specific DNA alkylation.

HDAC6 inhibition is associated with antiproliferative activity and apoptosis. $\mathrm{C} 1 \mathrm{~A}$ inhibited the growth of a panel of 17 human
A

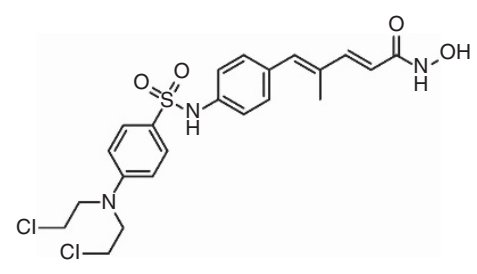

B

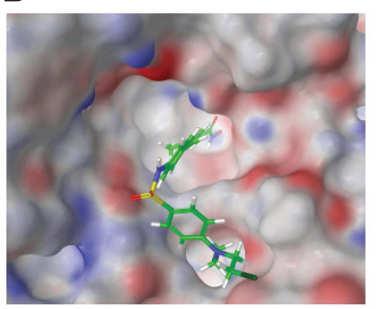

C

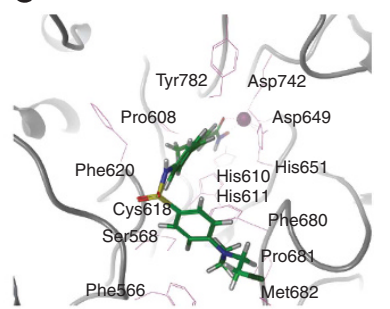

$\mathbf{F}$

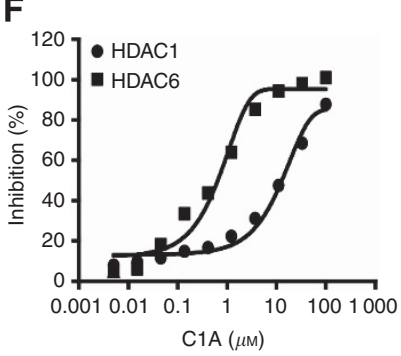

Figure 1. Enhanced specificity of C1A towards HDAC6 versus HDAC1. (A) Chemical structure of C1A. (B-E) Representative structures of the homology models of HDAC6 catalytic domain, (HDAC6cdll; 3D solvent accessible surface area (B); 3D ribbon diagram showing key amino acid interactions $(\mathbf{C})$ and $\mathrm{HDAC} 1 \mathrm{~cd}$ (3D solvent accessible surface area (D); 3D ribbon diagram showing key amino acid interactions (E) with C1A bound to the $\mathrm{Zn}^{2+}$ in the active site. Electrostatic surface colouring in $\mathbf{B}$ and $\mathbf{D}$ are red (negative charge) and blue (positive charge). ( $\mathbf{F}$ ) Inhibition of recombinant HDAC6 and HDAC1 by C1A. 


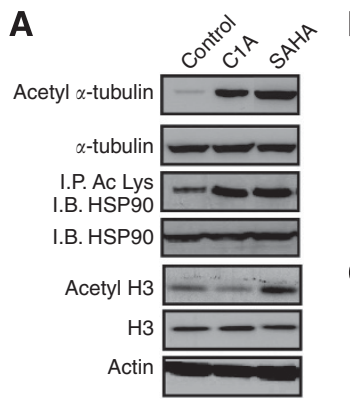

D
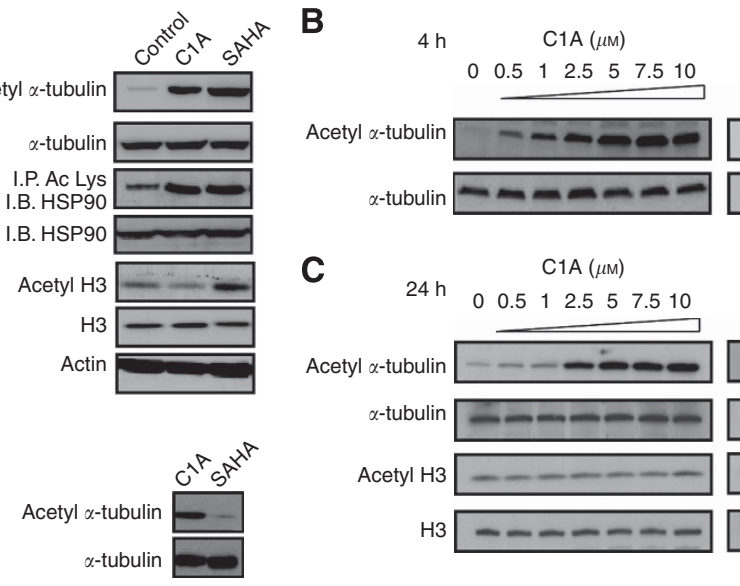

SAHA $(\mu \mathrm{m})$

$\begin{array}{lllll}0 & 0.050 .1 & 0.5 & 1 & 5\end{array}$

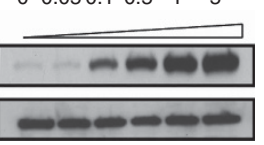

C

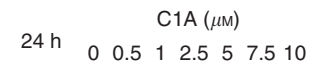

SAHA $(\mu \mathrm{m})$

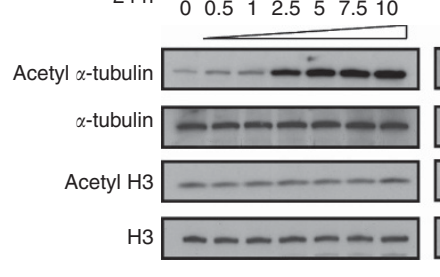

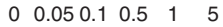

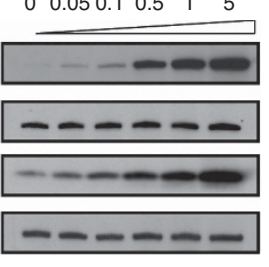

E

$\mathrm{C} 1 \mathrm{~A}(\mu \mathrm{m})$

SAHA $(\mu \mathrm{M})$

17-AAG (nM)
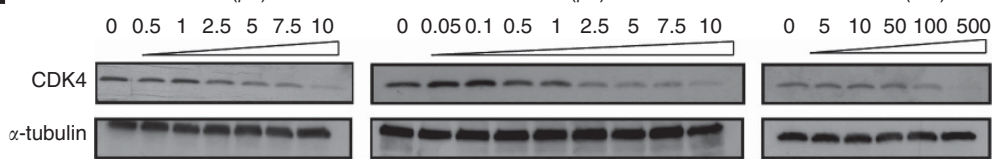

$\mathbf{F}$
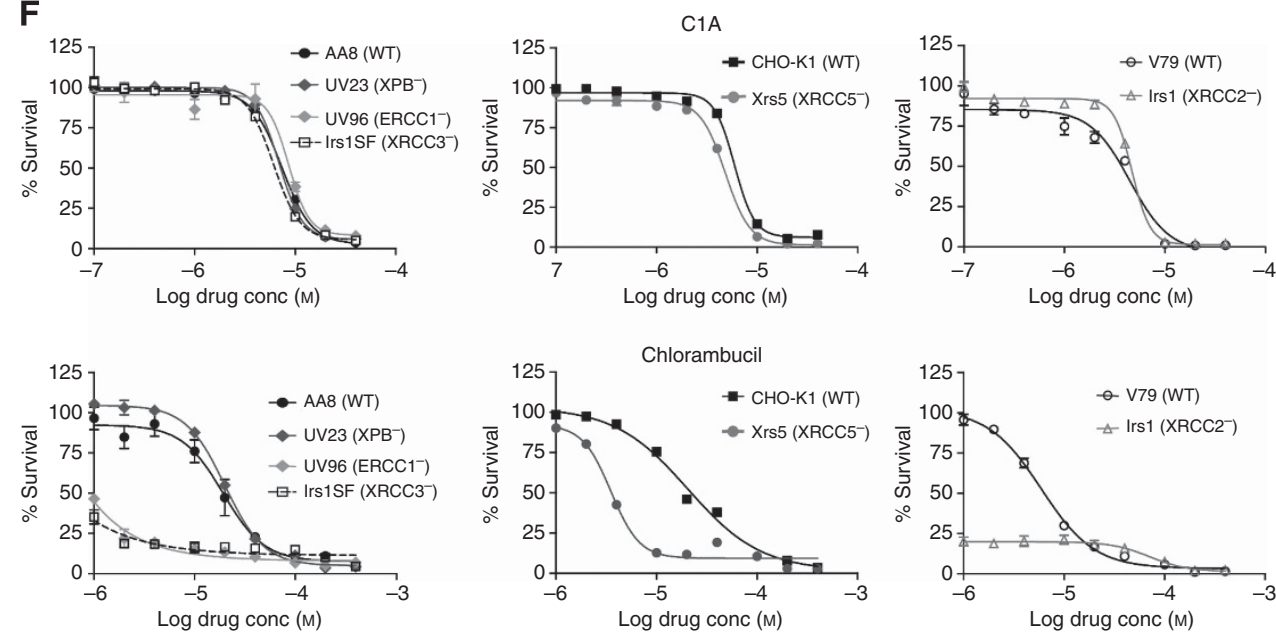

Figure 2. $\mathrm{C} 1 \mathrm{~A}$ is a selective inhibitor of HDAC6 associated with a sustained effect. (A) Inhibition of HDAC6 substrates by $\mathrm{C} 1 \mathrm{~A}(1 \mu \mathrm{M} ; 4 \mathrm{~h})$ relative to SAHA in HCT-116 cells. (B) Drug concentration-dependent acetylation of $\alpha$-tubulin at $4 \mathrm{~h}$, and (C) at $24 \mathrm{~h}$ relative to acetyl histone $\mathrm{H} 3$ expression. (D) Effect of $10 \mu \mathrm{m} \mathrm{C1A}$ or SAHA on acetylation of $\alpha$-tubulin in HCT-116 cells following $4 \mathrm{~h}$ drug incubation and washout (cells collected $3 \mathrm{~h}$ after washout). (E) Cognate effect of C1A and SAHA and C1A on HSP90 client protein CDK4 following 24h treatment. The HSP90 inhibitor, 17-AAG, was used as a positive control. (F) Effect of C1A on the growth of DNA repair-deficient and repair-competent cells relative to chlorambucil. UV23 and UV96 cell lines are deficient in XPB and ERCC1, respectively; proteins involved in the nucleotide excision repair pathway. Irs1 and Irs1SF are deficient in XRCC2 and XRCC3, respectively; proteins involved in the homologous recombination repair pathway. XRS5 is deficient in XRCC5; protein involved in the non-homologous end-joining pathway. Growth curves in parental repair-competent cell lines AA8 (for UV23, UV96 and Irs1SF), CHO-K1 (for XRS5) and V79 (for Irs1) are also presented.

cancer cell lines, including cell lines derived from 8 different histological types of solid tumours and one type of B-cell malignancy, with a mean growth inhibitory effect $\left(\mathrm{GI}_{50}\right)$ of $3.1 \pm 2.2 \mu \mathrm{m}$ following $72 \mathrm{~h}$ continuous exposure (Table 1 ). When the cells were treated for $6 \mathrm{~h}$, washed and allowed to grow for an additional $72 \mathrm{~h}$ in drug-free growth medium, the growth inhibitory effect of C1A was more than 300-fold greater than for SAHA (Figure 3A). Under washout conditions, the latter did not show any antiproliferative effect at the concentrations tested. The cellular effect of C1A was further characterised in HCT-116 cells to investigate the mechanism of growth inhibition. Flow cytometry studies showed that treatment of cells with $\mathrm{C} 1 \mathrm{~A}$ for $24 \mathrm{~h}$ increased the sub-G1 population in a drug concentration-related manner (from $4 \%$ in untreated cells to $64 \%$ at the highest concentration tested, i.e. $10 \mu \mathrm{M}$; Figure $3 \mathrm{~B}$ and $\mathrm{C}$ ), suggesting an apoptotic mechanism. The characteristic increased sub-G1 fraction was also demonstrated in A2780 human ovarian cancer cell line but not in the caspase-3-deficient human breast cancer cell line, MCF7 (Supplementary Figure S3; Janicke, 2009). In contrast, SAHA increased the fraction of cells arrested in G2/M (from 30-41\%) in the HCT-116 cells. SAHA also induced a sub-G1 population, but unlike $\mathrm{C} 1 \mathrm{~A}$ this effect reached a plateau at $22 \%$ from a low drug concentration. We confirmed the drug-induced increase in sub-G1 as occurring via apoptosis by measuring caspase-3/7 activity: both $\mathrm{C} 1 \mathrm{~A}$ and SAHA induced a drug concentration-related increase in caspase-3/7 activity (Figure 3D); increased caspase-3/7 activity was further confirmed in HCT-116 cells by flow cytometry (FLICA positive/SYTOX red negative; Supplementary Figure S4). Drug concentration-dependent increase in caspase-3/7 activity was also seen in these cells with tubastatin A (Supplementary Figure S5). 


\begin{tabular}{|c|c|c|c|}
\hline Cell type & Cell line & $\mathrm{C} 1 \mathrm{~A}(\mu \mathrm{M})$ & SAHA $(\mu \mathrm{M})$ \\
\hline Breast & $\begin{array}{c}\text { MCF7 } \\
\text { MDA-MB-435 } \\
\text { T47D }\end{array}$ & $\begin{array}{l}3.3 \pm 0.15 \\
7.7 \pm 0.2 \\
4.5 \pm 0.03\end{array}$ & $\begin{array}{c}3.5 \pm 0.6 \\
0.96 \pm 0.05 \\
1.2 \pm 0.2\end{array}$ \\
\hline $\begin{array}{l}\text { Colon } \\
\text { Endometrial } \\
\text { Epidermal } \\
\text { Lung } \\
\text { Myeloma }\end{array}$ & $\begin{array}{c}\text { HCT-116 } \\
\text { Ishikawa } \\
\text { A431 } \\
\text { A549 } \\
\text { ARH-77 } \\
\text { KMS-11 }\end{array}$ & $\begin{aligned} 3.3 & \pm 1.6 \\
5.6 & \pm 0.03 \\
4.1 & \pm 0.6 \\
5.8 & \pm 2 \\
3 & \pm 0.55 \\
0.48 & \pm 0.24\end{aligned}$ & $\begin{array}{c}0.48 \pm 0.1 \\
0.67 \pm 0.05 \\
1.1 \pm 0.1 \\
1.8 \pm 0.6 \\
0.48 \pm 0.24 \\
0.27 \pm 0.03\end{array}$ \\
\hline Neuroblastoma & $\begin{array}{l}\text { SH-SY5Y } \\
\text { Kelly } \\
\text { S-K-NAS } \\
\text { BE2C }\end{array}$ & $\begin{array}{c}0.28 \pm 0.01 \\
0.18 \pm 0.01 \\
3.3 \pm 1.5 \\
0.66 \pm 0.19\end{array}$ & $\begin{array}{c}0.92 \pm 0.3 \\
0.4 \pm 0.12 \\
0.49 \pm 0.02 \\
0.63 \pm 0.08\end{array}$ \\
\hline Ovarian & $\begin{array}{l}\text { A2780 } \\
\text { IGROV1 }\end{array}$ & $\begin{array}{c}0.96 \pm 0.44 \\
1.1 \pm 0.2\end{array}$ & $\begin{array}{r}0.82 \pm 0.1 \\
1.2 \pm 0.2\end{array}$ \\
\hline Prostate & $\begin{array}{l}\text { LNCAP } \\
\text { DU-145 }\end{array}$ & $\begin{array}{l}3.7 \pm 1.5 \\
4.6 \pm 0.6\end{array}$ & $\begin{array}{c}1.7 \pm 1.2 \\
0.54 \pm 0.01\end{array}$ \\
\hline
\end{tabular}

Caspase-3/7 activation by C1A also occurred in A2780 cell line but not in the caspase-3-deficient MCF7 breast cancer cell line (Supplementary Figure S3). Proliferation of cells transfected with HDAC6 shRNA was inhibited by $24 \%$ after 3 days of seeding, but unlike drug treatment no difference in caspase-3/7 activity was detectable (Supplementary Figure S6). Flow cytometry studies revealed that, cells transfected with HDAC6 shRNA had an increased sub-G1 population (from $1.2 \%$ for shRNA-scramble to $31.8 \%$ for shRNA HDAC6), suggesting that the peak of caspase-3/7 may have occurred at an earlier time point.

The cell cycle inhibition caused by SAHA was accompanied by an increase of the cyclin-CDK inhibitor p21 that was previously shown to be a consequence of histone hyperacetylation induced by broad-spectrum inhibitors targeting largely HDAC Class I (Richon et al, 2000; Wilson et al, 2006; Figure 3E). In contrast, p21 levels remained unchanged following treatment with $\mathrm{C} 1 \mathrm{~A}$. These studies suggests that the preferential activity of C1A on HDAC6 inhibited cell growth and induced cell death in a variety of cell lines.

We then tested whether different levels of HDAC6 protein expression may have an impact on $\mathrm{C} 1 \mathrm{~A}$-induced growth inhibition. HDAC6 was found to be ubiquitously expressed and no significant differences were seen between the cancer cell lines tested compared with HDAC1 (Supplementary Figure S7). There was no relationship between the growth inhibitory effect of $\mathrm{C} 1 \mathrm{~A}$ and HDAC6 nor HDAC1 protein expression (Supplementary Figure S7).

HDAC6 inhibition results in antitumour activity. Encouraged by our results in vitro, and against the background that HDAC6 inhibitors reported to date have poor PKs, we then wanted to know whether C1A could achieve sufficient plasma levels in vivo. The PKs of C1A followed a two-compartment model with an apparent terminal half-life of $10 \mathrm{~h}$ (Figure 4A). Maximum drug concentration was rapidly achieved ( $30 \mathrm{~min})$ when given i.p. Notably, drug levels equivalent to two-fold $\mathrm{GI}_{50}$ in $\mathrm{HCT}-116$ cells could be achieved following administration of $\mathrm{C} 1 \mathrm{~A}$ at $20 \mathrm{mg} \mathrm{kg}^{-1}$. C1A exhibited linear PK characteristics with dose-proportional increases observed in plasma concentration (Figure 4B).

Next, we tested if the potent in vitro activity of $\mathrm{C} 1 \mathrm{~A}$ combined with its favourable PK features favoured efficacy in the human cancer xenograft models. Different schedules and dose levels of C1A were tested in the HCT-116 xenograft model and antitumour activity was found to be dose-related. Doubling times were $4.4 \pm 1.1,8.3 \pm 1.0,7.6 \pm 1.2$ and $9.5 \pm 1.5$ days for vehicle control
A

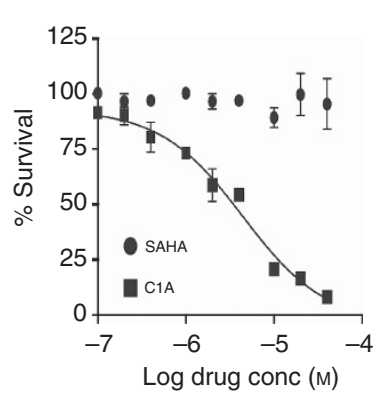

C

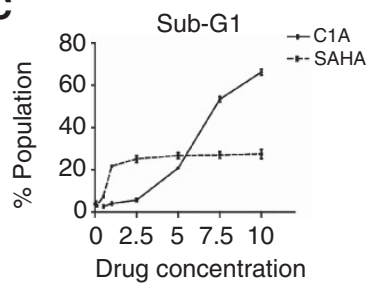

$(\mu \mathrm{M})$

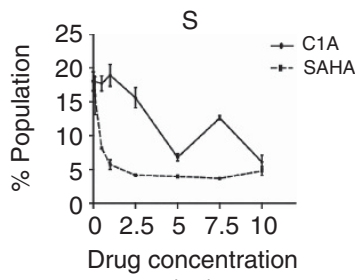

$(\mu \mathrm{M})$

D

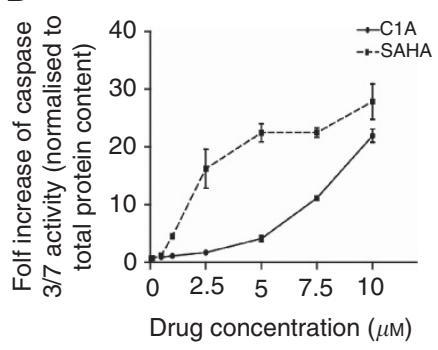

Figure 3. Effect of C1A on proliferation and apoptosis. (A) Growth inhibitory effect of C1A and SAHA in HCT-116 cells following $6 \mathrm{~h}$ drug incubation, wash and incubation in drug-free medium for an additional $72 \mathrm{~h}$. (B-C) HCT-116 cells were treated with C1A or SAHA for $24 \mathrm{~h}$ and DNA profile analysed by flow cytometry. (D) Effect of C1A or SAHA treatment $(24 \mathrm{~h})$ on caspase-3/7 activity. (E) Effect of C1A or SAHA (24h-10 $\mu \mathrm{m}$ ) on p21 expression in HCT-116 cells.

mice and mice treated with $\mathrm{C} 1 \mathrm{~A}$ at $40 \mathrm{mg} \mathrm{kg}^{-1}$ q.o.d., $20 \mathrm{mg} \mathrm{kg}^{-1}$ q.d. and $20 \mathrm{mg} \mathrm{kg}^{-1}$ b.i.d., respectively; Figure 4C). C1A treatment was associated with a tumour growth delay $\left(\mathrm{TGD}_{2 \mathrm{x}}\right)$ of $4.0 \pm 0.8$, $3.8 \pm 1.2$ and $5.7 \pm 1.4$ days and a tumour growth inhibition (TGI) of 57,69 and $78 \%$ compared with vehicle at $40 \mathrm{mg} \mathrm{kg}^{-1}$ q.o.d., $20 \mathrm{mg} \mathrm{kg}^{-1}$ q.d. and $20 \mathrm{mg} \mathrm{kg}^{-1}$ b.i.d., respectively; there was no general toxicity in any of the treated cohorts as determined by changes in body weight (Figure 4D).

In vivo antitumour activity is associated with molecular and imaging biomarker changes. Biochemical target modulation in vivo was determined by measuring levels of acetylated $\alpha$-tubulin in HCT-116 tumours. Following a single dose of $\mathrm{C} 1 \mathrm{~A}$ at $40 \mathrm{mg} \mathrm{kg}^{-1}$, acetylated $\alpha$-tubulin could be detected at $6 \mathrm{~h}$ and sustained up to $24 \mathrm{~h}$ (Figure 5A). No modulation of acetylation of histone $\mathrm{H} 3$ was detectable, confirming a lack of inhibitory effect on 

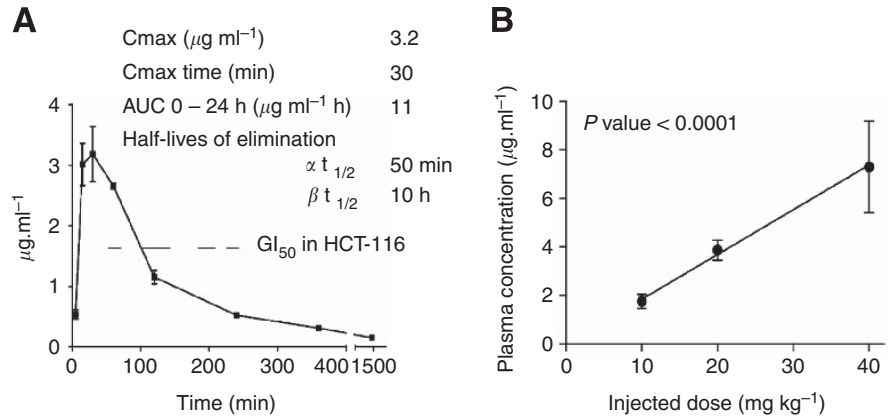

C

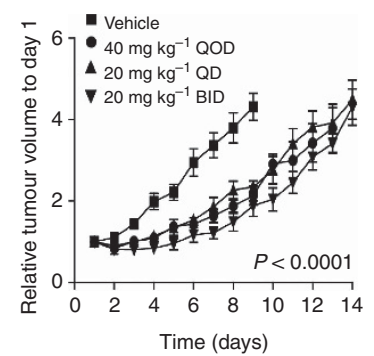

D

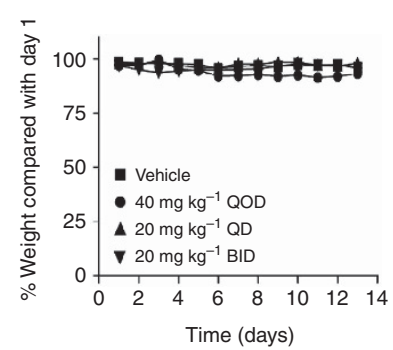

Figure 4. $\mathrm{C} 1 \mathrm{~A}$ is associated with favourable pharmacokinetic profile and significant antitumour activity. (A) Pharmacokinetic profile of C1A following a single i.p. injection at $20 \mathrm{mg} \mathrm{kg}^{-1}(n=3)$. (B) Dose-dependent relationship of the pharmacokinetic profile $1 \mathrm{~h}$ post injection $(n=3)$. (C) Effect of C1A on tumour growth in HCT-116 colon tumour xenograft model $(n=6)$. ANOVA was done to determine statistical significance between group control and each group treated with C1A. (D) Shown are the weights of the animals used in the time course of the study.

A

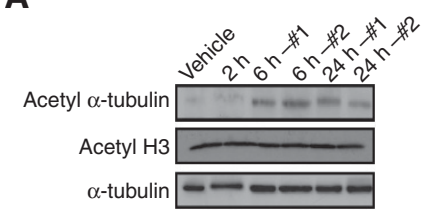

D $\Delta$ Caspase-3

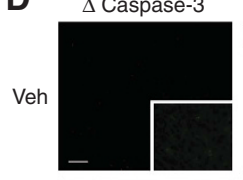

C1A
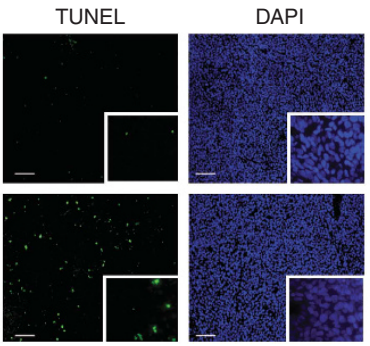

B

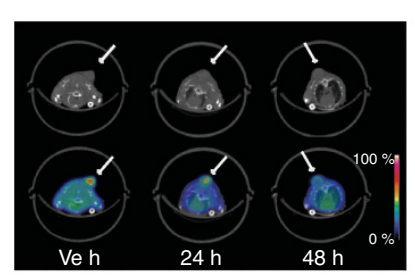

DAP

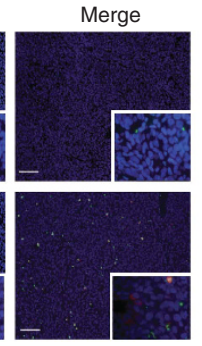

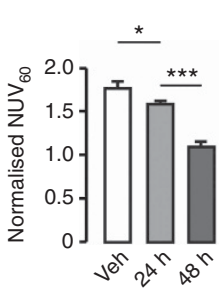

C
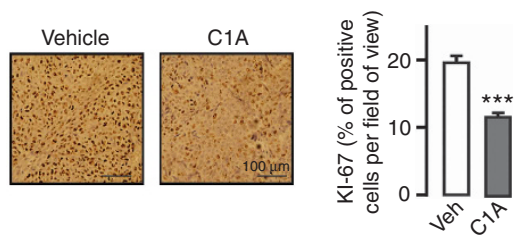

E
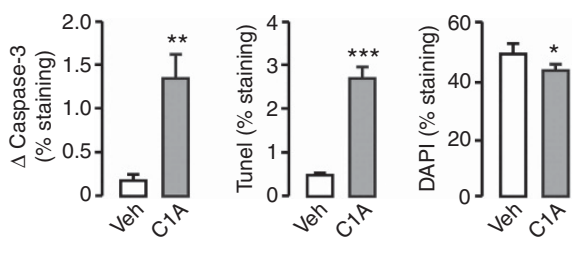

Figure 5. Molecular and imaging biomarkers for monitoring the response to C1A. Nude mice bearing HCT-116 tumour xenografts were injected with either vehicle or $\mathrm{C} 1 \mathrm{~A}$ at $40 \mathrm{mg} \mathrm{kg}^{-1}$ per day. (A) Expression of acetylated $\alpha$-tubulin and $\mathrm{H} 3$ over time following a single injection of $\mathrm{C} 1 \mathrm{~A}$ at $40 \mathrm{mg} \mathrm{kg}^{-1}$. (B) Computed tomography (CT; top) and corresponding $\left[{ }^{18} \mathrm{~F}\right]-\mathrm{FLT}-\mathrm{PET}-\mathrm{CT}$ (bottom). For visualisation, cumulative images up to 60 min are displayed. The tumour is indicated by an arrow. Quantitative $\left[{ }^{18} \mathrm{~F}\right]-\mathrm{FLT}$ uptake at 24 and $48 \mathrm{~h}$ was expressed as radiotracer uptake in tumours normalised to that of heart at $60 \mathrm{~min}\left(\mathrm{NUV}_{60} ; n=4\right)$. (C) Ki-67 immunostained tumour sections following treatment for 2 days. Proliferative cells have brown staining. Ki-67 labelling index was calculated from 10 random fields of view per slice (2 slices per tumour, and 3 tumours per group). The Ki-67-positive cells were expressed as a percentage of total cells. (D) Tumour active caspase-3 and TUNEL immunohistochemistry analysis. Tumour tissues were removed after PET imaging (following treatment for 2 days) and stained for active (cleaved) caspase-3 ( $\Delta$ caspase-3) and DNA fragmentation (TUNEL assay). Representative images of histological tumour sections are shown. Staining intensities were expressed as per cent staining per field using 10 random fields of view per slice (2 slices per tumour and 3 tumours per group). (E) Differential gene expression of HCT116 tumours $24 \mathrm{~h}$ following a single injection of $\mathrm{C} 1 \mathrm{~A}$ at $40 \mathrm{mg} \mathrm{kg}^{-1}$ and compared with vehicle-treated $(n=3)$.

class I HDACs. Furthermore, tumour uptake of the proliferation imaging biomarker, $\left[{ }^{18} \mathrm{~F}\right] \mathrm{FLT}$ (Shields et al, 1998; Leyton et al, 2006a), decreased after C1A treatment (Figure 5B). Radioactivity in tumour regions normalised to that of the heart of the same animal was used quantitatively to compare the effects of C1A (Leyton et al, 2006a). There was a 1.7 -fold decrease in tumour $\left[{ }^{18} \mathrm{~F}\right] \mathrm{FLT}$ uptake in animals treated with $\mathrm{C} 1 \mathrm{~A}$ for $48 \mathrm{~h}$ compared with vehicletreated mice; $\mathrm{NUV}_{60}$ was $1.77 \pm 0.11$ before treatment and decreased to $1.59 \pm 0.10 \quad(P=0.033)$ at $24 \mathrm{~h}$ and $1.06 \pm 0.15$ $(P=0.0001)$ at $48 \mathrm{~h}$ after initiating treatment (Figure 5B). Ki-67 immunostaining decreased in these tumours in keeping with the reduction in tumour $\left[{ }^{18} \mathrm{~F}\right] \mathrm{FLT}$ uptake $(1.7$-fold; $P<0.0001)$ (Figure 5C). We further evaluated if $\mathrm{C} 1 \mathrm{~A}$ induced apoptosis in vivo. Activated caspase-3 expression and subsequent fragmented DNA staining (TUNEL) increased 6- $(P=0.0082)$ and 7 -fold
$(P<0.0001)$, respectively, together with a decrease of DNA content $(P=0.023$; Figure 5D).

Gene expression signature following C1A treatment in vivo. Although HDAC6 has been described as being predominantly cytoplasmic, it has also been suggested to act as a nuclear cofactor (Palijan et al, 2009). To assess if the mechanism of response to $\mathrm{C} 1 \mathrm{~A}$ in vivo was related at least in part to transcriptional activation, directly or indirectly via its substrates, a gene array was performed in the HCT-116 xenograft model. Of the 20000 genes tested, only 13 were deregulated $(0.065 \%)$ at $24 \mathrm{~h}$ following a single injection of $\mathrm{C1A}\left(40 \mathrm{mg} \mathrm{kg}^{-1}\right)$ in keeping with the class II (HDAC6) effect of C1A (i.e., minor effect in the regulation of genes; Figure 5E) in contrast to SAHA (LaBonte et al, 2009). The following genes were upregulated: BST2, FHL1, 
NBPF(8-11, 14-16), XAF1, PIP5KL1, BAX, SRD5A1, DHCR24, TAPBP, PTPRG, IPO7 and RAD23B; HIST2H2AC was downregulated. Among those, the pro-apoptotic factors XAF1 (gene encoding XIAP-associated factor 1 , an antagonist of X-linked inhibitor of apoptosis protein) and $B A X$ (gene encoding Bcl-2associated $\mathrm{X}$ protein) were upregulated, which could explain in part the antitumour activity. Of note is the upregulation of $R A D 23 B$ that was recently proposed as a predictive marker of response to HDACIs generally (Fotheringham et al, 2009). To confirm changes in protein expression, western blot analysis was performed on the excised tumours. Levels of XAF1, PIP5KL1 and RAD23B were indeed higher following treatment with $\mathrm{C} 1 \mathrm{~A}$ (Supplementary Figure S8).

\section{DISCUSSION}

Cancer remains an unmet medical need with one in three people affected by the disease. New therapies with improved efficacy and reduced side effect profile are needed. We have shown that a potent small molecule inhibitor of HDAC, in particular HDAC6, inhibits proliferation and induces cell death in tumour cells lines from diverse histological background.

There is an increasing interest in HDAC6 as a therapeutic target. Although HDAC6 inhibitors including tubacin and tubastatin A (Haggarty et al, 2003; Butler et al, 2010) have been reported, the lack of inhibitors with favourable PK profile has stifled progress within the field. More recently, a new HDAC6 inhibitor ACY-1215 was reported as an inhibitor of multiple myeloma cell growth when combined with bortezomib (Santo et al, 2012). The chemical structure of ACY-1215 is not available for comparison and the effect of ACY-1215 on solid tumours was not evaluated in that study. We report the mechanism of action and growth inhibitory properties of a new HDACI, C1A in a solid tumour model. HCT-116 xenograft model was chosen because it represented the highest HDAC6 expression, has intermediate sensitivity to C1A (thus, data are not biased to high sensitivity tumours only) and it has been used extensively as a model for other HDACIs, including genomic and imaging studies (Leyton et al, 2006a; Witter et al, 2008; LaBonte et al, 2009). Furthermore, there is a need to develop therapies for colorectal cancer, which accounts for $10-15 \%$ of all cancers and is the second leading cause of cancer deaths in western countries. Traditionally used for nearly 50 years, 5-fluorouracil (5-FU) has led to a small benefit in survival (Buyse et al, 1988). More recently, combination regimens comprising of 5-FU leuvorin irinotecan, cetuximab or oxiloplatin have been used to improve clinical efficacy. When tested as monotherapy in preclinical models of colon cancer, these compounds demonstrate only modest activity. We hypothesised that treatment with $\mathrm{C} 1 \mathrm{~A}$ could offer benefit over conventional chemotherapy.

C1A was designed to have sustained duration of HDAC inhibitory activity via an aromatic nitrogen mustard moiety. Interestingly, we found that $\mathrm{C} 1 \mathrm{~A}$ had preferential HDAC6 activity in vitro. Molecular modelling analysis suggested favourable interaction between $\mathrm{C} 1 \mathrm{~A}$ and HDA6cdII relative to the unfavourable binding of the aniline mustard of $\mathrm{C} 1 \mathrm{~A}$ to a solvent-exposed groove within HDAC1cd. These physicochemical properties of C1A probably explain preferential acetylation of known HDAC6 substrates, $\alpha$-tubulin and HSP90 in vitro, compared with SAHA, which is a pan-HDACI. By making comparisons with SAHA (being a current clinically approved HDACI, as well as having sufficiently different selectivity profile (Bradner et al, 2010)), we show that $\mathrm{C} 1 \mathrm{~A}$ is mechanistically novel with a mechanism of action more in keeping with the HDAC6 selective inhibitor toolcompound tubastatin A. Phenotypic effects of HDAC6 knockdown by shRNA overlapped with those of C1A treatment, including inhibition of proliferation, increase in sub-G1 fraction, increased of acetylation of $\alpha$-tubulin and decreased CDK4 expression with unremarkable changes in acetylation of histone $\mathrm{H} 3$ providing further confidence in the specificity of C1A towards HDAC6.

$\mathrm{C} 1 \mathrm{~A}$ was potent in the low micromolar range across a diverse range of cancer cell lines. The presence of a sub-G1 population together with caspase-3/7 induction suggested that the drug may act via an apoptotic mechanism. Further studies are required to elucidate the exact mechanism leading to apoptosis. We speculate that drug potency profile could be due, in part, to acetylation of cytoplasmic proteins, including HSP90 and $\alpha$-tubulin, which have pivotal roles in tumour progression. HSP90 is involved in the maturation of several oncogenic client proteins, the degradation of which could abrogate cell growth and induce apoptosis (Maloney and Workman, 2002). Acelylation of $\alpha$-tubulin, which promotes microtubule stabilisation, may distort mitosis and trigger apoptosis (Matsuyama et al, 2002); it can also affect changes in cell motility and, hence, invasion and metastasis of cancer cells (Hubbert et al, 2002). Further work is required to directly link inhibition of C1A targets to growth inhibition. It is possible that the presence of an aromatic nitrogen mustard moiety may independently induce cell death. We examined this possibility in cell lines proficient and deficient in DNA repair. These studies (Figure 2F) suggested that the mustard moiety in $\mathrm{C} 1 \mathrm{~A}$ does not induce non-specific DNA alkylation and, thus, unlikely to significantly contribute to a DNA alkylation-dependent cell death. We wondered if HDAC6 expression in the different cell lines might predict sensitivity to C1A. This did not appear to be the case as HDAC6 was ubiquitously expressed with no significant differences across cell lines. Furthermore, the differences in growth sensitivity between the cell lines were only $\sim 10$-fold. Future studies in a larger cohort of cell lines may provide the possibility to confirm this finding.

Unlike HDAC6 tool compounds like tubastatin A, C1A had favourable $\mathrm{PKs}$ in vivo, and systemic administration of the drug inhibited the growth of colon tumours in vivo by up to $78 \%$. Consistent with proposed mechanism of action, we observed a time-dependent induction of $\alpha$-tubulin in tumours of mice treated with $\mathrm{C} 1 \mathrm{~A}$, with no change in histone $\mathrm{H} 3$ in tumours. Future studies that specifically investigate multiple tolerable dose levels in xenograft bearing mice - HCT-116 and other tumour types - will confirm or disprove the biological relevance of $\alpha$-tubulin as a pharmacodynamic biomarker in tumours. Imaging biomarkers also provide a means to extend pre-clinical findings into the design of innovative clinical trials of novel agents. In this regard, C1A treatment reduced tumour $\left[{ }^{18} \mathrm{~F}\right] \mathrm{FLT}$ uptake by 1.7 -fold at $48 \mathrm{~h}$, suggesting that molecular imaging could provide value in future studies of this compound. $\left[{ }^{18} \mathrm{~F}\right]$ FLT-PET uptake was previously shown to be altered only at later time points with broad-spectrum HDACI LAQ-824 (Leyton et al, 2006a). The imaging output was consistent with the observed reduction in Ki-67 immunostaining in excised tumour samples.

In keeping with the preferential HDAC6 activity, the drug showed restricted activity on gene expression in vivo with $<0.065 \%$ of genes modulated during $24 \mathrm{~h}$ of treatment. Notably, however, although HDAC6 modulation was seen in vivo, we cannot wholly attribute the changes in gene expression seen after C1A treatment to an HDAC6 mechanism, as we cannot completely rule out accumulation of $\mathrm{C} 1 \mathrm{~A}$ into the tumour cells to levels high enough to also inhibit other HDAC classes. The lack of an increase in histone $\mathrm{H} 3$ acetylation together with the absence of typical gene expression profile characteristic of class I HDAC inhibition, for instance activation of CDKNIA that encodes p21WAF1/CIP1, suggest that the observed gene expression profile was not due to inhibition of class I HDAC. As per the in vitro studies, the observation that $\mathrm{C} 1 \mathrm{~A}$ induced pro-apoptotic genes including XAF1 and $B A X$ requires further investigation. 
In conclusion, C1A preferentially inhibits HDAC6 and modulates HDAC6 downstream targets, leading to growth inhibition of a diverse set of cancer cell lines. This property together with the favourable PKs and efficacy in vivo makes it a candidate for further pre-clinical and clinical development. Acetyl$\alpha$-tubulin and $\left[{ }^{18} \mathrm{~F}\right]$ FLT-PET hold promise as pharmacodynamic and efficacy biomarkers in the clinical testing of C1A. These interesting results provide a rationale for the future development of HDAC6 inhibitors to treat patients with solid tumours.

\section{ACKNOWLEDGEMENTS}

This study was supported by CR-UK \& EPSRC Cancer Imaging Centre at Imperial College, London, in association with the MRC and Department of Health (England) grant number C2536/A10337.

\section{CONFLICT OF INTEREST}

The authors declare no conflict of interest.

\section{REFERENCES}

Balasubramanian S, Ramos J, Luo W, Sirisawad M, Verner E, Buggy JJ (2008) A novel histone deacetylase 8 (HDAC8)-specific inhibitor PCI-34051 induces apoptosis in T-cell lymphomas. Leukemia 22(5): 1026-1034.

Bali P, Pranpat M, Bradner J, Balasis M, Fiskus W, Guo F, Rocha K, Kumaraswamy S, Boyapalle S, Atadja P, Seto E, Bhalla K (2005) Inhibition of histone deacetylase 6 acetylates and disrupts the chaperone function of heat shock protein 90: a novel basis for antileukemia activity of histone deacetylase inhibitors. J Biol Chem 280(29): 26729-26734.

Banerji U, Walton M, Raynaud F, Grimshaw R, Kelland L, Valenti M, Judson I, Workman P (2005) Pharmacokinetic-pharmacodynamic relationships for the heat shock protein 90 molecular chaperone inhibitor 17allylamino, 17-demethoxygeldanamycin in human ovarian cancer xenograft models. Clin Cancer Res 11(19 Pt 1): 7023-7032.

Boyault C, Sadoul K, Pabion M, Khochbin S (2007) HDAC6, at the crossroads between cytoskeleton and cell signaling by acetylation and ubiquitination. Oncogene 26(37): 5468-5476.

Bradner JE, West N, Grachan ML, Greenberg EF, Haggarty SJ, Warnow T, Mazitschek R (2010) Chemical phylogenetics of histone deacetylases. Nat Chem Biol 6(3): 238-243.

Bruserud O, Stapnes C, Ersvaer E, Gjertsen BT, Ryningen A (2007) Histone deacetylase inhibitors in cancer treatment: a review of the clinical toxicity and the modulation of gene expression in cancer cell. Curr Pharm Biotechnol 8(6): 388-400.

Butler KV, Kalin J, Brochier C, Vistoli G, Langley B, Kozikowski AP (2010) Rational design and simple chemistry yield a superior, neuroprotective HDAC6 inhibitor, tubastatin A. J Am Chem Soc 132(31): 10842-10846.

Buyse M, Zeleniuch-Jacquotte A, Chalmers TC (1988) Adjuvant therapy of colorectal cancer. Why we still don't know. JAMA 259(24): 3571-3578.

Duvic M, Vu J (2007) Vorinostat: a new oral histone deacetylase inhibitor approved for cutaneous T-cell lymphoma. Expert Opin Investig Drugs 16(7): 1111-1120.

Finnin MS, Donigian JR, Cohen A, Richon VM, Rifkind RA, Marks PA, Breslow R, Pavletich NP (1999) Structures of a histone deacetylase homologue bound to the TSA and SAHA inhibitors. Nature 401(6749): 188-193.

Fotheringham S, Epping MT, Stimson L, Khan O, Wood V, Pezzella F, Bernards R, La Thangue NB (2009) Genome-wide loss-of-function screen reveals an important role for the proteasome in HDAC inhibitor-induced apoptosis. Cancer Cell 15(1): 57-66.

Haberland M, Montgomery RL, Olson EN (2009) The many roles of histone deacetylases in development and physiology: implications for disease and therapy. Nat Rev Genet 10(1): 32-42.

Haggarty SJ, Koeller KM, Wong JC, Grozinger CM, Schreiber SL (2003) Domain-selective small-molecule inhibitor of histone deacetylase 6
(HDAC6)-mediated tubulin deacetylation. Proc Natl Acad Sci USA 100(8): 4389-4394.

Hubbert C, Guardiola A, Shao R, Kawaguchi Y, Ito A, Nixon A, Yoshida M, Wang XF, Yao TP (2002) HDAC6 is a microtubule-associated deacetylase. Nature 417(6887): 455-458.

Janicke RU (2009) MCF-7 breast carcinoma cells do not express caspase-3. Breast Cancer Res Treat 117(1): 219-221.

Kaluza D, Kroll J, Gesierich S, Yao TP, Boon RA, Hergenreider E, Tjwa M, Rossig L, Seto E, Augustin HG, Zeiher AM, Dimmeler S, Urbich C (2011) Class IIb HDAC6 regulates endothelial cell migration and angiogenesis by deacetylation of cortactin. EMBO J 30(20): 4142-4156.

Kawada J, Zou P, Mazitschek R, Bradner JE, Cohen JI (2009) Tubacin kills Epstein-Barr virus (EBV)-Burkitt lymphoma cells by inducing reactive oxygen species and EBV lymphoblastoid cells by inducing apoptosis. J Biol Chem 284(25): 17102-17109.

Kazantsev AG, Thompson LM (2008) Therapeutic application of histone deacetylase inhibitors for central nervous system disorders. Nat Rev Drug Discov 7(10): 854-868.

LaBonte MJ, Wilson PM, Fazzone W, Groshen S, Lenz HJ, Ladner RD (2009) DNA microarray profiling of genes differentially regulated by the histone deacetylase inhibitors vorinostat and LBH589 in colon cancer cell lines. BMC Med Genomics 2: 67.

Lahm A, Paolini C, Pallaoro M, Nardi MC, Jones P, Neddermann P, Sambucini S, Bottomley MJ, Lo Surdo P, Carfi A, Koch U, De Francesco R, Steinkuhler C, Gallinari P (2007) Unraveling the hidden catalytic activity of vertebrate class IIa histone deacetylases. Proc Natl Acad Sci USA 104(44): 17335-17340.

Lee YS, Lim KH, Guo X, Kawaguchi Y, Gao Y, Barrientos T, Ordentlich P, Wang XF, Counter CM, Yao TP (2008) The cytoplasmic deacetylase HDAC6 is required for efficient oncogenic tumorigenesis. Cancer Res 68(18): 7561-7569.

Leyton J, Alao JP, Da Costa M, Stavropoulou AV, Latigo JR, Perumal M, Pillai R, He Q, Atadja P, Lam EW, Workman P, Vigushin DM, Aboagye EO (2006a) In vivo biological activity of the histone deacetylase inhibitor LAQ824 is detectable with 3'-deoxy-3'[18F]fluorothymidine positron emission tomography. Cancer Res 66(15): 7621-7629.

Leyton J, Lockley M, Aerts JL, Baird SK, Aboagye EO, Lemoine NR, McNeish IA (2006b) Quantifying the activity of adenoviral E1A CR2 deletion mutants using renilla luciferase bioluminescence and 3'-deoxy3 '-[18F]fluorothymidine positron emission tomography imaging. Cancer Res 66(18): 9178-9185.

Leyton J, Smith G, Lees M, Perumal M, Nguyen QD, Aigbirhio FI, Golovko O, He Q, Workman P, Aboagye EO (2008) Noninvasive imaging of cell proliferation following mitogenic extracellular kinase inhibition by PD0325901. Mol Cancer Ther 7(9): 3112-3121.

Maloney A, Workman P (2002) HSP90 as a new therapeutic target for cancer therapy: the story unfolds. Expert Opin Biol Ther 2(1): 3-24.

Marks PA, Xu WS (2009) Histone deacetylase inhibitors: Potential in cancer therapy. J Cell Biochem 107(4): 600-608.

Marsoni S, Damia G, Camboni G (2008) A work in progress: the clinical development of histone deacetylase inhibitors. Epigenetics 3(3): 164-171.

Matsuyama A, Shimazu T, Sumida Y, Saito A, Yoshimatsu Y, SeigneurinBerny D, Osada H, Komatsu Y, Nishino N, Khochbin S, Horinouchi S, Yoshida M (2002) In vivo destabilization of dynamic microtubules by HDAC6-mediated deacetylation. EMBO J 21(24): 6820-6831.

Nguyen QD, Smith G, Glaser M, Perumal M, Arstad E, Aboagye EO (2009) Positron emission tomography imaging of drug-induced tumor apoptosis with a caspase-3/7 specific [18F]-labeled isatin sulfonamide. Proc Natl Acad Sci USA 106(38): 16375-16380.

Palijan A, Fernandes I, Bastien Y, Tang L, Verway M, Kourelis M, Tavera-Mendoza LE, Li Z, Bourdeau V, Mader S, Yang XJ, White JH (2009) Function of histone deacetylase 6 as a cofactor of nuclear receptor coregulator LCoR. J Biol Chem 284(44): 30264-30274.

Parmigiani RB, Xu WS, Venta-Perez G, Erdjument-Bromage H, Yaneva M, Tempst P, Marks PA (2008) HDAC6 is a specific deacetylase of peroxiredoxins and is involved in redox regulation. Proc Natl Acad Sci USA 105(28): 9633-9638.

Piekarz RL, Frye R, Turner M, Wright JJ, Allen SL, Kirschbaum MH, Zain J, Prince HM, Leonard JP, Geskin LJ, Reeder C, Joske D, Figg WD, Gardner ER, Steinberg SM, Jaffe ES, Stetler-Stevenson M, Lade S, Fojo AT, Bates SE (2009) Phase II multi-institutional trial of the histone deacetylase inhibitor 
romidepsin as monotherapy for patients with cutaneous T-cell lymphoma. J Clin Oncol 27(32): 5410-5417.

Richon VM, Sandhoff TW, Rifkind RA, Marks PA (2000) Histone deacetylase inhibitor selectively induces p21WAF1 expression and gene-associated histone acetylation. Proc Natl Acad Sci USA 97(18): 10014-10019.

Rivieccio MA, Brochier C, Willis DE, Walker BA, D'Annibale MA, McLaughlin K, Siddiq A, Kozikowski AP, Jaffrey SR, Twiss JL, Ratan RR, Langley B (2009) HDAC6 is a target for protection and regeneration following injury in the nervous system. Proc Natl Acad Sci USA 106(46): 19599-19604.

Santo L, Hideshima T, Kung AL, Tseng JC, Tamang D, Yang M, Jarpe M, van Duzer JH, Mazitschek R, Ogier WC, Cirstea D, Rodig S, Eda H, Scullen T, Canavese M, Bradner J, Anderson KC, Jones SS, Raje N (2012) Preclinical activity, pharmacodynamic, and pharmacokinetic properties of a selective HDAC6 inhibitor, ACY-1215, in combination with bortezomib in multiple myeloma. Blood 119(11): 2579-2589.

Schultz BE, Misialek S, Wu J, Tang J, Conn MT, Tahilramani R, Wong L (2004) Kinetics and comparative reactivity of human class I and class IIb histone deacetylases. Biochemistry 43(34): 11083-11091.

Scroggins BT, Robzyk K, Wang D, Marcu MG, Tsutsumi S, Beebe K, Cotter RJ, Felts S, Toft D, Karnitz L, Rosen N, Neckers L (2007) An acetylation site in the middle domain of Hsp90 regulates chaperone function. Mol Cell 25(1): 151-159.

Shields AF, Grierson JR, Dohmen BM, Machulla HJ, Stayanoff JC, LawhornCrews JM, Obradovich JE, Muzik O, Mangner TJ (1998) Imaging proliferation in vivo with [F-18]FLT and positron emission tomography. Nat Med 4(11): 1334-1336.

Vichai V, Kirtikara K (2006) Sulforhodamine B colorimetric assay for cytotoxicity screening. Nat Protoc 1(3): 1112-1116.
Wilson AJ, Byun DS, Popova N, Murray LB, L'Italien K, Sowa Y, Arango D, Velcich A, Augenlicht LH, Mariadason JM (2006) Histone deacetylase 3 (HDAC3) and other class I HDACs regulate colon cell maturation and p21 expression and are deregulated in human colon cancer. J Biol Chem 281(19): 13548-13558.

Witt O, Deubzer HE, Milde T, Oehme I (2009) HDAC family: What are the cancer relevant targets? Cancer Lett 277(1): 8-21.

Witter DJ, Harrington P, Wilson KJ, Chenard M, Fleming JC, Haines B, Kral AM, Secrist JP, Miller TA (2008) Optimization of biaryl Selective HDAC1\&2 Inhibitors (SHI-1:2). Bioorg Med Chem Lett 18(2): 726-731.

Workman P, Aboagye EO, Balkwill F, Balmain A, Bruder G, Chaplin DJ, Double JA, Everitt J, Farningham DA, Glennie MJ, Kelland LR, Robinson V, Stratford IJ, Tozer GM, Watson S, Wedge SR, Eccles SA (2010) Guidelines for the welfare and use of animals in cancer research. Br J Cancer 102(11): 1555-1577.

Xu WS, Parmigiani RB, Marks PA (2007) Histone deacetylase inhibitors: molecular mechanisms of action. Oncogene 26(37): 5541-5552.

Zhang X, Yuan Z, Zhang Y, Yong S, Salas-Burgos A, Koomen J, Olashaw N, Parsons JT, Yang XJ, Dent SR, Yao TP, Lane WS, Seto E (2007) HDAC6 modulates cell motility by altering the acetylation level of cortactin. Mol Cell 27(2): 197-213.

(c) (i) (2) (2) This work is licensed under the Creative Commons Attribution-NonCommercial-Share Alike 3.0 Unported License. To view a copy of this license, visit http://creativecommons. org/licenses/by-nc-sa/3.0/

Supplementary Information accompanies this paper on British Journal of Cancer website (http://www.nature.com/bjc) 